\title{
Lactobacillus plantarum GKM3 Promotes Longevity, Memory Retention, and Reduces Brain Oxidation Stress in SAMP8 Mice
}

\author{
Shih-Wei Lin ${ }^{1}$, You-Shan Tsai ${ }^{2}$ (D), Yen-Lien Chen ${ }^{2}$, Ming-Fu Wang ${ }^{3}$, Chin-Chu Chen ${ }^{4,5,6}$, Wen-Hsin Lin ${ }^{7, *(D)}$ \\ and Tony J. Fang ${ }^{1, *}$
}

1 Department of Food Science and Biotechnology, National Chung Hsing University, Taichung 402204, Taiwan; wei.lin@grapeking.com.tw

2 Biotech Research Institute, Grape King Bio Ltd., Taoyuan 325002, Taiwan; you.shan.tsai@gmail.com (Y.-S.T.); lan.chen@grapeking.com.tw (Y.-L.C.)

3 Department of Food and Nutrition, Providence University, Taichung 433303, Taiwan; mfwang@pu.edu.tw

4 Institute of Food Science and Technology, National Taiwan University, Taipei 106319, Taiwan; gkbioeng@grapeking.com.tw

5 Department of Food Science, Nutrition and Nutraceutical Biotechnology, Shih Chien University, Taipei 104336, Taiwan

6 Department of Bioscience Technology, Chung Yuan Christian University, Taoyuan 320314, Taiwan

7 Department of Pharmacy, China Medical University, Taichung 404333, Taiwan

* Correspondence: wslin@mail.cmu.edu.tw (W.-H.L.); tjfang@nchu.edu.tw (T.J.F.); Tel.: +886-4-2205-3366 (W.-H.L.); +886-4-2284-0385 (T.J.F.)

check for updates

Citation: Lin, S.-W.; Tsai, Y.-S.; Chen, Y.-L.; Wang, M.-F.; Chen, C.-C.; Lin, W.-H.; Fang, T.J. Lactobacillus plantarum GKM3 Promotes Longevity, Memory Retention, and Reduces Brain Oxidation Stress in SAMP8 Mice. Nutrients 2021, 13, 2860. https://doi.org/10.3390/ nu13082860

Academic Editor:

Malgorzata Muc-Wierzgon

Received: 21 July 2021

Accepted: 19 August 2021

Published: 20 August 2021

Publisher's Note: MDPI stays neutral with regard to jurisdictional claims in published maps and institutional affiliations.

Copyright: (c) 2021 by the authors. Licensee MDPI, Basel, Switzerland. This article is an open access article distributed under the terms and conditions of the Creative Commons Attribution (CC BY) license (https:// creativecommons.org/licenses/by/ $4.0 /)$.

\begin{abstract}
Background: An age-related cognitive decline is commonly affecting the life of elderly with symptoms involved in progressive impairments to memory and learning. It has been proposed that probiotics could modulate age-related neurological disorders via the gut-brain axis. (2) Methods: To investigate the anti-aging effect of probiotic Lactobacillus plantarum GKM3, both survival tests and cognitive experiments were conducted in the SAMP8 mice model. The sixmonth-old SAMP8 $\left(n=20\right.$ in each gender) were fed with probiotic GKM3 at a dosage of $5.1 \times 10^{9}$ and $1.0 \times 10^{9} \mathrm{cfu} / \mathrm{kg} \mathrm{B.W./day} \mathrm{until} \mathrm{their} \mathrm{natural} \mathrm{death.} \mathrm{Then,} \mathrm{the} \mathrm{life} \mathrm{span} \mathrm{was} \mathrm{investigated.}$ Three-month-old SAMP8 ( $\mathrm{n}=10$ in each gender) were administered GKM3 for 14 weeks. Then, the behavior tests and oxidation parameters were recorded. (3) Results: GKM3 groups showed significantly increased latency in the passive avoidance test and time of successful avoidance in the active avoidance test. The TBARS and 8-OHdG from mice brains also showed a significant reduction in the groups treated with GKM3. In addition, lower accumulation of the amyloid- $\beta$ protein was found in SAMP8 mice brains with the supplement of GKM3. (4) Conclusions: These results indicated that L. plantarum GKM3 delayed the process of aging, alleviated age-related cognitive impairment, and reduced oxidative stress.
\end{abstract}

Keywords: senescence accelerated mouse prone 8 (SAMP8); probiotics; 8-hydroxy-2'-deoxyguanosine (8-OHdG); thiobarbituric acid-reactive substances (TBARS); amyloid- $\beta$ (A $\beta$ ); aging

\section{Introduction}

It has been an issue that population-suffered cognitive impairment has become bigger following the growth of the amount of older individuals in the last decade [1]. According to the report from the World Health Organization (WHO), the number of people with cognitive decline, which was more than 46.8 million in 2015, will reach over 74.7 million in 2030, which is almost increased by half within fifteen years [2]. Aging, recognized as a strong correlation with cognitive impairment, is generally thought to be associated with oxidative stress, which is involved in the accumulation of free radicals and promoted many physiological dysfunctions especially in the brain, an oxygen-sensitive organ, leading to degenerative symptoms such as memory loss and decline of learning ability [3-5]. 
As aging is inevitable and its relative negative symptoms are complicated, people pursue treatments for anti-aging, ranging from diet therapies to more than drug treatments [6,7]. For example, ginseng (Panax quinquefolius) root extract demonstrated improved cognitive function and was marked as a favorite by the Koreans [8]. Ginkgo biloba extract, another example, was loved by the Japanese for its functions in cognitive enhancing and oxidation-reduction [9]. Although many reports have suggested that the plant-based diets provide antioxidant effects and retard the aging process, there are more interesting focuses on the gut microbiota or even on a group of specific bacteria in the gut that could metabolize these nutraceuticals and provide positive multi-modulation effects to the host, including longevity [10-14]. Gut bacteria could produce short-chain fatty acids (SCFAs) such as acetate, propionate, or butyrate from one's diet [15]. Children who consumed plant-based enteral nutrition showed higher SCFAs than the normal kids in their stool samples [16]. These SCFAs can play an important role in the human gastrointestinal epithelium [17]. Acetate can cross the blood-brain barrier, inducing hypothalamic neuronal activation [18]. In addition, butyrate has been studied regarding the effect of suppressing colonic inflammation in the human gut [19]. Therefore, it matters what kind of microbiota or specific bacteria is in the human gut, especially in terms of influencing body health and longevity [20,21].

The intestinal microbiota also can impact the gut-brain axis and delay the process of aging, thereby preventing the progress of age-related diseases such as amnesia, dementia, or even Alzheimer's disease [22,23]. The neurotransmitter gamma-aminobutyric acid (GABA), for example, could be produced by certain bacteria strains that have been reported with the proliferation of epithelial stem cells in the gut and the improvement of depressivelike behavior in mice [24,25]. With current supportive data, the addition of probiotics as a prevention method has been a trend for these age-related neurological disorders [26,27].

Lactobacillus is the most common probiotic that showed a high possibility of developing functional food as it has existed in human food for a long time [28]. However, individual bacterial species have unique bioactivities, from strains to strains, that require experimental confirmation. In our previous studies, we isolated the probiotic strain Lactobacillus plantarum GKM3 from pickled leaf (Brassica juncea), also known as the longevity vegetable in Taiwanese Hakka society, and conducted functional studies on boosting the gastrointestinal tract and immunity in vivo [29-31]. Therefore, we expected the likelihood of L. plantarum GKM3 alleviating the process of aging and age-related cognitive impairment.

\section{Materials and Methods}

\subsection{Subjects}

L. plantarum GKM3 was isolated from Chinese mustard (Brassica juncea) and preserved at the Bioresource Collection and Research Center, Taiwan (BCRC), with the collection number 910787. First, GKM3 was cultured with a MRS (BD Co., Franklin Lakes, NJ, USA) broth at $37{ }^{\circ} \mathrm{C}$ for $18 \mathrm{~h}$ in the test tube. With $0.01 \%$ inoculation, the GKM3 seed culture was scaled up in $50 \mathrm{~L}$ fermenter under a pH 6.0 control at $37^{\circ} \mathrm{C}$ for $18 \mathrm{~h}$ with a designed medium ( $5 \%$ glucose, $2 \%$ yeast extract, $0.05 \% \mathrm{MgSO}_{4}, 0.1 \% \mathrm{~K}_{2} \mathrm{HPO}_{4}$, and $0.1 \%$ Tween 80 ). Then, the fermented bacteria were harvested by centrifugation at $3800 \mathrm{rpm}$ for $10 \mathrm{~min}$, washed with phosphate saline buffer twice, and the pellet was mixed with $10 \%$ milk for lyophilization. The dosages of L. plantarum GKM3 freeze-dried powder in this study were adjusted to $5.1 \times 10^{9} \mathrm{cfu} / \mathrm{kg}$ B.W./day as the high dose and $1.0 \times 10^{9} \mathrm{cfu} / \mathrm{kg}$ B.W./day as the low dose for the mouse model by gavage.

The senescence-accelerated prone mice P8 (SAMP8) were introduced in this study as an aging animal model. All SAMP8 mice were applied and kept at $12 \mathrm{~h}$ dark/light cycle under $25 \pm 2{ }^{\circ} \mathrm{C}, 65 \pm 5 \% \mathrm{RH}$ with food and water ad libitum. The following experimental procedures were approved by the Animal Management Committee of the Department of Food and Nutrition, Providence University (Taichung City, Taiwan), with the IACUC number 20170629-A02. 


\subsection{Survival Test}

In the survival test, six-month-old SAMP8 mice were grouped with 20 females and 20 males as follows: control, GKM3 high-dose group, and GKM3 low-dose group. Probiotic L. plantarum GKM3 was daily supplied to the treatment mice until they reached their natural death. The live/dead SAMP8 mice in each group were recorded and the average lifespans were calculated.

\subsection{Experiment Design for Age-Related Cognitive Impairment}

Three-month-old SAMP8 mice were housed for the cognitive impairment experiment. Both male and female SAMP8 mice were grouped as follows ( $\mathrm{n}=10$ in each gender): control group, GKM3 high-dose group, and GKM3 low-dose group. The mice in the treatment groups were orally administered L. plantarum GKM3 for 14 weeks. The locomotion activity was conducted on the 11th week of the experiment. The passive avoidance test and active avoidance test were respectively conducted on the 13th and 14th week, and then mice were sacrificed for biochemical analysis and histological examination.

\subsection{Locomotion Activity}

Each mouse was placed in the center of a shuttle cage $(25 \mathrm{~cm} \times 25 \mathrm{~cm} \times 25 \mathrm{~cm}$, Coulbourn Instruments Model E61-21, Lehigh, PA, USA) and their locomotions were recorded by an activity monitor video-path analyzer for $10 \mathrm{~min}$. The average time of mouse movement was analyzed every $5 \mathrm{~min}(\mathrm{~s} / 5 \mathrm{~min}$ ). This procession was conducted under dim light and silent conditions.

\subsection{Passive Avoidance Test}

A shuttle cage $(35 \mathrm{~cm} \times 17 \mathrm{~cm} \times 20 \mathrm{~cm}$, Coulbourn Instruments Model E10-15, Lehigh, PA) was parted into a dark and light room. There was a guillotine door $(7.5 \mathrm{~cm} \times 6.5 \mathrm{~cm}$, Coulbourn Instruments Model E10-15GD, Lehigh, PA, USA) between the two rooms. In the training test for the passive avoidance test, a mouse was placed in the light room for a minute adaptation and then the guillotine door was opened. The mouse would receive $0.5 \mu \mathrm{A}$ electric shock for $0.5 \mathrm{~s}$ when it entered the dark room. The shock continually occurred three times every five seconds. The mouse was replaced under the same operation at $24 \mathrm{~h}, 48 \mathrm{~h}$, and $72 \mathrm{~h}$ after the training session for the memory test, except that no shock was delivered. The average times of mice staying in the light room were measured. An upper cutoff time of $180 \mathrm{~s}$ was set.

\subsection{Active Avoidance Test}

In the training test for the active avoidance test, the mouse would receive a $10 \mathrm{~s}$ conditioned stimulus (CS) based on light and sound, and then $5 \mathrm{~s}$ of $0.3 \mathrm{~mA}$ electric shock (unconditional stimulus, UCS) if the mouse stayed in the same room, whereas, there was no shock reception if the mouse moved to the other room. Each mouse had trained for 5 CS and UCS cycles. The mouse was tested under the same operation (CS/UCS system) with 15-20 min intertrial intervals four times a day and continually tested for four days. The average avoidance time was measured as the effect of learning memory.

\subsection{Oxidative Stress Analysis}

For the detection of 8-hydroxy-2'-deoxyguanosine (8-OHdG) from the brain mitochondrial DNA, $30 \mathrm{mg}$ of brain tissue was extracted by the Blood \& Tissue Genomic DNA Extraction Miniprep System (Viogene Biotek Corp., Taipei, Taiwan) and the highly sensitive 8-OHdG Check ELISA Kit (Nikken SEIL Co. Ltd., Shizuoka, Japan) was applied with an absorbance at $450 \mathrm{~nm}$. For the thiobarbituric acid-reactive substances (TBARS) analysis, $25 \mathrm{mg}$ of brain tissue was ground with $250 \mu \mathrm{L}$ RIPA buffer and centrifuged at $16,000 \times g$ for 10 min under $4{ }^{\circ} \mathrm{C}$. In total, $100 \mu \mathrm{L}$ of supernatant was collected and added with $100 \mu \mathrm{L}$ SDS solution and $4 \mathrm{~mL}$ color reagent, then boiled for an hour before the cooling treatment. Treated samples were centrifuged at $16,000 \times g$ for $10 \mathrm{~min}$ and placed for $30 \mathrm{~min}$ at room 
temperature. The TBARS content (mM/g protein) from each $150 \mu \mathrm{L}$ sample was measured at $535 \mathrm{~nm}$ absorbance with the standard curve.

\subsection{Measurements of the Brain Amyloid- $\beta$ Protein}

The amyloid- $\beta(A \beta)$ protein from the brain tissue section was stained by the method of immunohistochemistry. The percentage of $A \beta$ accumulation was analyzed by image system (Leica, Q500, Wetzlar, Germary) with a microscope under a $40 \times$ field. The calculation was based on the percentage of the $A \beta$ accumulation area in all of the brain: ( $\beta$-amyloid deposition area/whole brain area) $\times 100 \%$.

\subsection{Histology}

The brains were excised and fixed with 10\% formalin. The hippocampal tissue was processed through the process of dehydration, cleaning, infiltration, and embedding for sectioning. Then, the tissue of the hippocampus area was examined by Hematoxylin and Eosin (H\&E) staining.

\subsection{Statistic}

The statistic stool SPSS 19.0 was used in this study. All data are expressed as mean \pm S.E.M. and evaluated by one-way ANOVA for the comparison of means between the different groups. A significant difference was considered when the $p$ value was less than 0.05 by Duncan's multiple range tests. In the survival test, the Kaplan-Meier test was applied for analysis and the log-rank test was conducted to verify the differences between groups.

\section{Results}

\subsection{Effect of L. plantarum GKM3 on the SAMP8 Survival Test}

In the survival experiment, the lifespan of SAMP8 mice was observed until their natural death and it took 21 months to complete all the individual records. The average lifespan of non-treated male SAMP8 mice were $11.90 \pm 0.18$ months and for females it was $11.20 \pm 0.21$ months. In the probiotic GKM3 feeding groups, the average male lifespan extended to $12.05 \pm 0.15$ months and $13.50 \pm 0.14$ months in low and high doses of GKM3 treatments, respectively. The dose-dependent effect of probiotic GKM3 on lifespan extension in females could also be observed with $12.15 \pm 0.21$ months in the low-dose group and with $14.30 \pm 0.17$ months in the high-dose treatment (data not shown).

To summarize life expectancy, the survival rate was estimated. With a $50 \%$ survival rate, the low dosage of GKM3 in the male group was 12.67 months and the high dosage of the GKM3 male group was 13.33 months, while the male control group only presented 12.50 months (Figure 1A). Similar to the observation in female SAMP8 mice, 12.00 months and 15.50 months with a $50 \%$ survival rate was showed in groups fed probiotic GKM3 at a dosage of $1.0 \times 10^{9} \mathrm{CFU} / \mathrm{kg} \mathrm{BW} /$ day and $5.1 \times 10^{9} \mathrm{CFU} / \mathrm{kg} \mathrm{BW} /$ day, respectively; however, 10.50 months with a $50 \%$ survival rate was observed in the female control group (Figure 1B). The female SAMP8 mice presented shorter life expectancies than males as the basis in this experiment; interestedly, the effect of L. plantarum GKM3 in terms of the lifespan had a greater impact on females. It is suggested that L. plantarum GKM3 can increase longevity in SAMP8 mice of both sexes, especially in female species. 
(A)

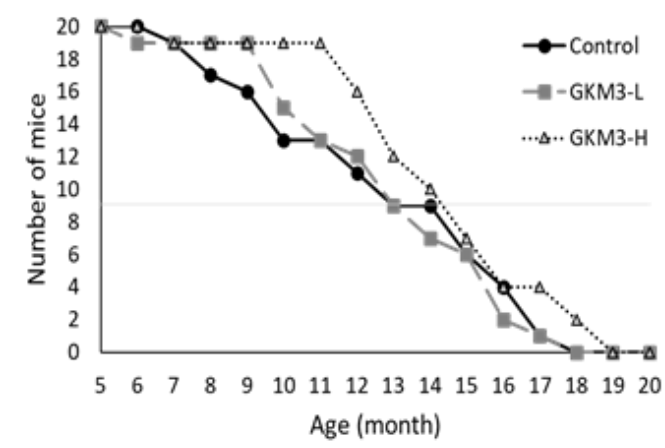

(B)

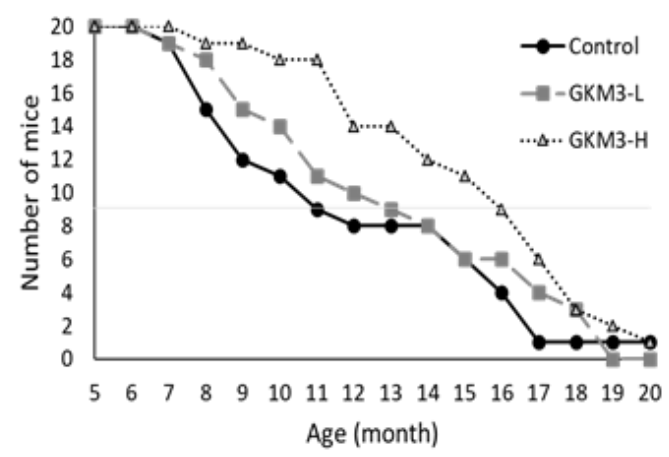

Figure 1. The lifespan of SAMP8 mice in males (A) and females (B). GKM3-L and GKM3-H were represent the groups fed probiotic GKM3 at the low dosage of $1.0 \times 10^{9} \mathrm{CFU} / \mathrm{kg} \mathrm{BW} /$ day and the high dosage of $5.1 \times 10^{9} \mathrm{CFU} / \mathrm{kg} \mathrm{BW} /$ day, respectively $(\mathrm{n}=10)$.

\subsection{Body Weight, Food Intake, and Water Intake in SAMP8 Mice}

In the experiment of aged-related cognitive impairment, there were no significant differences in the energy consumption and weight change among all the SAMP8 mice of the different treatment groups before the sacrifice (Table 1). This means that the probiotic GKM3 did not affect these metabolic parameters in the aged-mouse model.

Table 1. Body weight, food intake, and water consumption.

\begin{tabular}{|c|c|c|c|c|c|c|}
\hline \multirow[b]{2}{*}{ Sex } & \multirow[b]{2}{*}{ Group } & \multicolumn{3}{|c|}{ Body Weight (g) } & \multirow{2}{*}{$\begin{array}{l}\text { Food Intake } \\
\text { (g/day) }\end{array}$} & \multirow{2}{*}{$\begin{array}{c}\text { Water } \\
\text { Consumption } \\
\text { (mL/day) }\end{array}$} \\
\hline & & $\begin{array}{c}\text { Initial } \\
\text { (Week 0) }\end{array}$ & $\begin{array}{c}\text { Final } \\
\text { (Week 14th) }\end{array}$ & Gain & & \\
\hline \multirow{3}{*}{ Male } & Control & $28.37 \pm 1.03^{a}$ & $32.06 \pm 1.05^{b}$ & $3.69 \pm 0.47^{c}$ & $4.79 \pm 0.06^{\mathrm{d}}$ & $6.67 \pm 0.10^{\mathrm{e}}$ \\
\hline & GKM3-L & $28.81 \pm 0.78^{a}$ & $31.14 \pm 1.01^{b}$ & $2.33 \pm 0.36^{c}$ & $4.74 \pm 0.07^{\mathrm{d}}$ & $6.65 \pm 0.16^{\mathrm{e}}$ \\
\hline & GKM3-H & $28.58 \pm 0.76^{\mathrm{a}}$ & $32.12 \pm 1.03^{b}$ & $3.55 \pm 0.57^{\mathrm{c}}$ & $4.71 \pm 0.08^{\mathrm{d}}$ & $6.53 \pm 0.15^{\mathrm{e}}$ \\
\hline \multirow{3}{*}{ Female } & Control & $27.14 \pm 0.95^{f}$ & $27.61 \pm 0.87^{g}$ & $0.47 \pm 0.61^{h}$ & $4.09 \pm 0.04^{i}$ & $4.64 \pm 0.14^{j}$ \\
\hline & GKM3-L & $27.01 \pm 0.73^{f}$ & $28.05 \pm 0.85^{\mathrm{g}}$ & $1.49 \pm 0.70^{h}$ & $3.98 \pm 0.11^{\mathrm{i}}$ & $4.60 \pm 0.06^{j}$ \\
\hline & GKM3-H & $26.63 \pm 0.39^{f}$ & $28.51 \pm 0.84^{g}$ & $1.88 \pm 1.02^{h}$ & $4.10 \pm 0.14^{\mathrm{i}}$ & $4.69 \pm 0.07^{j}$ \\
\hline
\end{tabular}

Values are presented as mean \pm S.E.M., $\mathrm{n}=10$ (one-way ANOVA). Same alphabet letters represent no significant difference. GKM3-L: $1.0 \times 10^{9} \mathrm{CFU} / \mathrm{kg}$ BW/day (low dose); GKM3-H: $5.1 \times 10^{9} \mathrm{CFU} / \mathrm{kg}$ BW/day (high dose).

\subsection{Effect of L. plantarum GKM3 on Memory Retention and Learning Enhancement}

A locomotion activity test showed that there was no significant difference among all the SAMP8 mice in the first 5-min interval, regardless of gender (Table 2). Although there was a decrease in the second 5-min interval, when compared to the first 5-min interval, there was no significant change between the treated and non-treated groups.

Table 2. The locomotion activity of SAMP8 mice.

\begin{tabular}{cccc}
\hline \multirow{2}{*}{ Sex } & Group & \multicolumn{2}{c}{ Locomotion Time Interval (Minutes) } \\
\cline { 2 - 4 } & & $\mathbf{0 - 5}(\mathbf{s} / \mathbf{5} \mathbf{~ m i n})$ & $\mathbf{6 - 1 0} \mathbf{( s / 5 ~} \mathbf{~ m i n})$ \\
\hline \multirow{2}{*}{ Male } & Control & $94.90 \pm 7.91^{\mathrm{a}}$ & $86.40 \pm 5.89^{\mathrm{a}}$ \\
& GKM3-L & $111.10 \pm 4.95^{\mathrm{a}}$ & $84.80 \pm 6.36^{\mathrm{a}}$ \\
& GKM3-H & $92.70 \pm 2.93^{\mathrm{a}}$ & $80.20 \pm 3.74^{\mathrm{a}}$ \\
\hline \multirow{2}{*}{ Female } & Control & $85.10 \pm 8.24^{\mathrm{a}}$ & $84.10 \pm 6.12^{\mathrm{a}}$ \\
& GKM3-L & $88.10 \pm 4.79^{\mathrm{a}}$ & $72.10 \pm 6.93^{\mathrm{a}}$ \\
& GKM3-H & $121.20 \pm 16.25^{\mathrm{a}}$ & $117.70 \pm 6.93^{\mathrm{a}}$ \\
\hline
\end{tabular}

Values are presented as mean \pm S.E.M., $\mathrm{n}=10$ (one-way ANOVA). Same alphabet letters represent no significant difference. GKM3-L: $1.0 \times 10^{9} \mathrm{CFU} / \mathrm{kg}$ BW/day (low dose); GKM3-H: $5.1 \times 10^{9} \mathrm{CFU} / \mathrm{kg}$ BW/day (high dose). 
Passive avoidance tests were performed on male and female groups of SAMP8 mice (Figure 2). There were no significant differences among all the groups during the trial test $(p>0.05)$. The latency of SAMP8 male mice fed with probiotic GKM3 was significantly increased in a comparison to the control group on the first day $(p<0.05)$ (Figure 2A). The time of female SAMP8 mice staying in the light room was also increased on the first day in the GKM3 treatment, with a $p$-value of less than 0.05 in the low-dose group and a $p$-value of less than 0.01 in the high-dose group when compared to the control. However, there were no significant differences after the second day of the passive avoidance test. A longer latency performed in the GKM3 feeding group, both in male and female SAMP8 mice, indicated that probiotic GKM3 could contribute to age-related memory retention and learning enhancement.

(A)

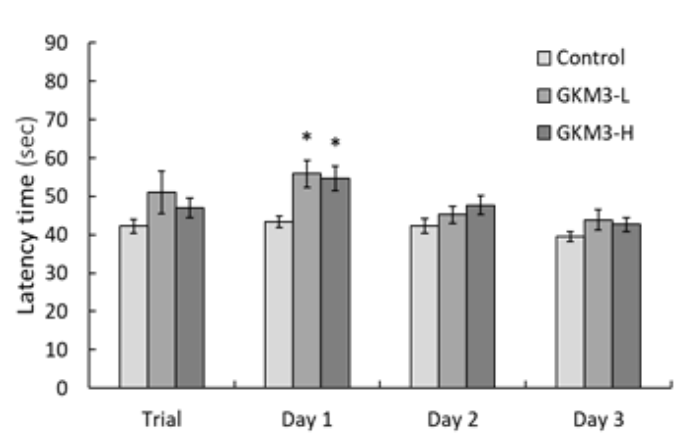

(B)

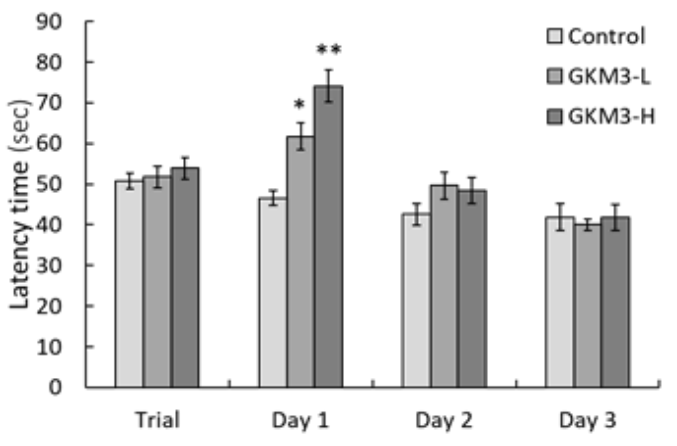

Figure 2. Passive avoidance ability of male (A) and female (B) SAMP8 mice. Values are presented as mean \pm S.E.M. $(\mathrm{n}=10) .{ }^{*} p<0.05$ and ${ }^{* *} p<0.01$ were regarded as a significant difference (one-way ANOVA). GKM3-L: $1.0 \times 10^{9} \mathrm{CFU} / \mathrm{kg}$ BW/day (low dose); GKM3-H: $5.1 \times 10^{9} \mathrm{CFU} / \mathrm{kg}$ BW/day (high dose).

In an active avoidance procedure, the mice were required to take any action to avoid the noxious stimulus. In the trial day of the active avoidance test, both the male and female SAMP8 mice fed with GKM3 showed a tendency of higher success in avoidance (Figure 3) but did not reach the statistic difference $(p>0.05)$ when compared with the control group. However, the result on day one and two of the active avoidance test showed that the successful time was significantly increased in the male groups with GKM3 fed when compared to the non-treated male SAMP8 mice (Figure $3 \mathrm{~A})(p<0.05)$. A similar result was also observed in the female groups (Figure 3B). Interestedly, there were no statistical differences ( $p=0.157)$ on the fourth day's result between the control and probiotic groups. This means that the control mice needed training for four days to catch up with the presence of the probiotic-fed mice. It is suggested that the addition of probiotic GKM3 to the diet could help the host's cognition which impacts the appropriate behavior in both genders. 
(A)

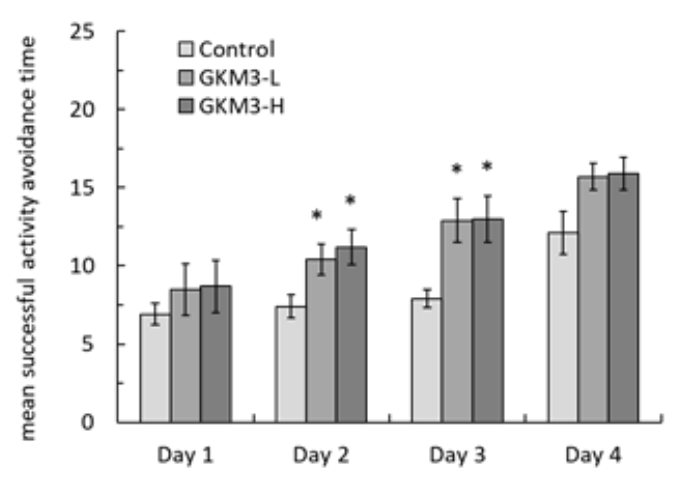

(B)

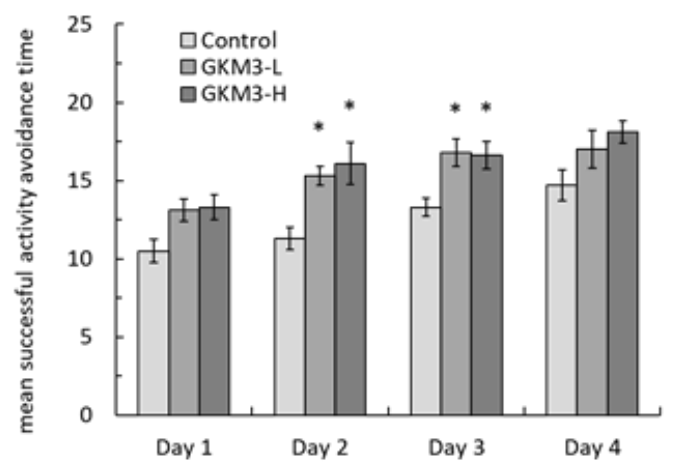

Figure 3. Active avoidance ability of male (A) and female (B) SAMP8 mice. Values are presented as mean \pm S.E.M. $(\mathrm{n}=10) .{ }^{*} p<0.05$ was regarded as a significant difference (one-way ANOVA). GKM3-L: $1.0 \times 10^{9} \mathrm{CFU} / \mathrm{kg}$ BW/day (low dose); GKM3-H: $5.1 \times 10^{9} \mathrm{CFU} / \mathrm{kg} \mathrm{BW} /$ day (high dose).

\subsection{Effect of L. plantarum GKM3 on Brain Oxidative Stress Reduction}

TBARS is a by-product of lipid peroxidation which could describe the level of oxidative stress. The concentration of TBARS was detected in SAMP8 mice brains after the sacrifice. Both male and female SAMP8 mice fed with probiotic GKM3 showed a significant reduction in the concentration of brain TBARS when compared to the control mice (Figure 4A). Another marker of oxidative stress, 8-OHdG, in the brain was also significantly lower in the GKM3 treatment group in a comparison to the non-treatment (Figure 4B). This indicates that less DNA damage occurred in the probiotic group. There were no dose-effects of GKM3 observed in brain TBARS and 8-OHdG levels in either both genders, suggesting the low dosage of probiotic GKM3, which was $1.0 \times 10^{9} \mathrm{CFU} / \mathrm{kg} \mathrm{BW} /$ day, was enough for the antioxidant defense in aged mice.

(A)

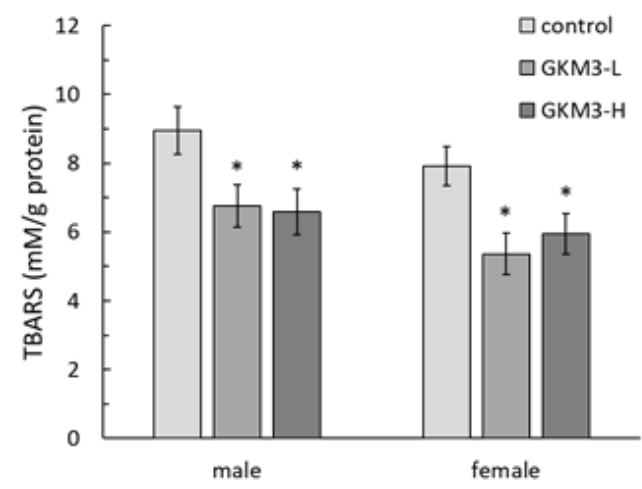

(B)

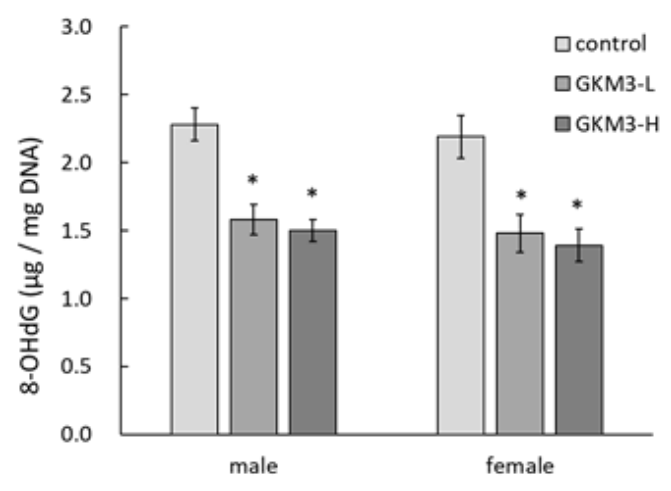

Figure 4. The TBARS (A) and 8-OHdG (B) level in SAMP8 mice brains after 14 weeks of probiotic GKM3 consumption. Values are presented as mean \pm S.E.M. $(\mathrm{n}=5) .{ }^{*} p<0.05$ was regarded as a significant difference (one-way ANOVA). GKM3-L: $1.0 \times 10^{9} \mathrm{CFU} / \mathrm{kg}$ BW/day (low dose); GKM3H: $5.1 \times 10^{9} \mathrm{CFU} / \mathrm{kg} \mathrm{BW} /$ day (high dose). Abbreviations: TBARS, thiobarbituric acid reactive substances and 8-OHdG, 8-hydroxy-2'-deoxyguanosine.

\subsection{Effect of L. plantarum GKM3 on Amyloid- $\beta$ Participation in SAMP8 Mice Brains}

Amyloid- $\beta(A \beta)$ precipitation is one of the characteristics in SAMP8 mice which shared the same features with dementia at the clinical observation. Figure 5 shows the immunohistochemical result of the SAMP8 brain tissue. The A $\beta$ precipitation was obviously observed in control male and female SAMP8 mice brains (Figure 5A,D), but little protein appeared on the samples of those treated with a low-dose of GKM3 (Figure 5B,E) and even less protein accumulated on those with the treatments with a high dose of GKM3 
(Figure $5 \mathrm{C}, \mathrm{F}$ ). The percentage of the A $\beta$ precipitation area in SAMP8 mice fed with probiotic GKM3 presented a significant reduction when compared to the controls in both genders (Figure 5G). This evidence revealed that L. plantarum GKM3 could prevent the age-related $A \beta$ precipitation, which may contribute to a neurological disorder.

(A)

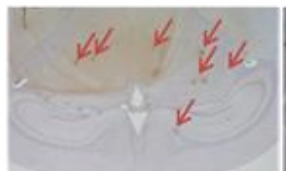

(D)

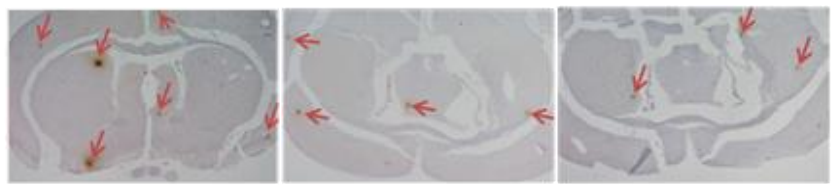

(B)

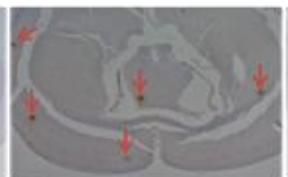

(E)
(C)

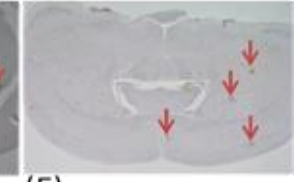

(F)

Figure 5. The $\beta$-amyloid participation in SAMP8 mice brains (40X) after 14 weeks of probiotic GKM3 consumption. (A): control male; (B): GKM3 low-dose male; (C): GKM3 high-dose male; (D): control female; (E): GKM3 low-dose female; (F): GKM3 high-dose female; and (G): the percentage of the amyloid- $\beta$ participation area. The arrows point to the participation of amyloid- $\beta$. Values are presented as mean \pm S.E.M. $(\mathrm{n}=5)$. ${ }^{*} p<0.05$ was regarded as a significant difference (oneway ANOVA).

\subsection{Effect of L. plantarum GKM3 on Hippocampus Histology in SAMP8 Mice}

The hippocampus of SAMP8 mice brains was analyzed by hematoxylin and eosin staining (Figure 6). There were hyperchromic staining with the shrinking of nerve cells presented on the control and GKM3 low-dose groups. However, the neuron in the hippocampus of SAMP8 fed with a high-dose of GKM3 showed a tight arrangement. In addition, there was no abnormal observation of the cell structure and morphology in the GKM3 high-dose group. This indicates that probiotic GKM3 could delay the neuron damage caused by aging in the hippocampus of mice brains.

Control

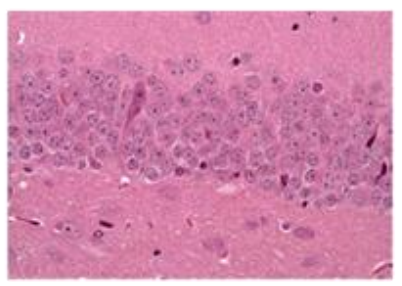

Male

Female

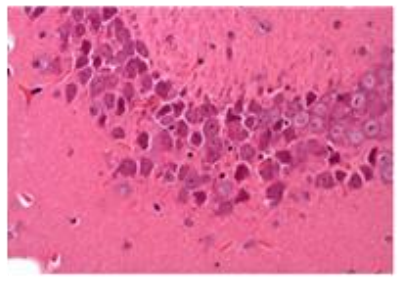

GKM3-L
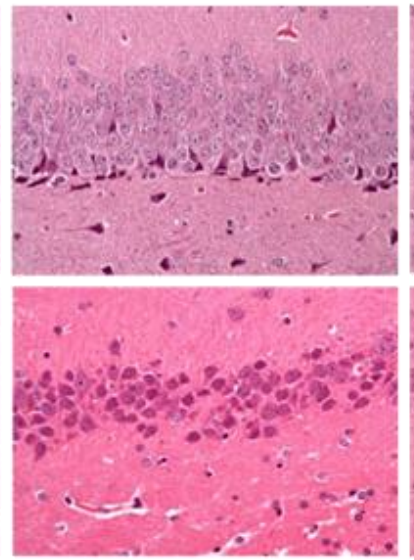

GKM3-H

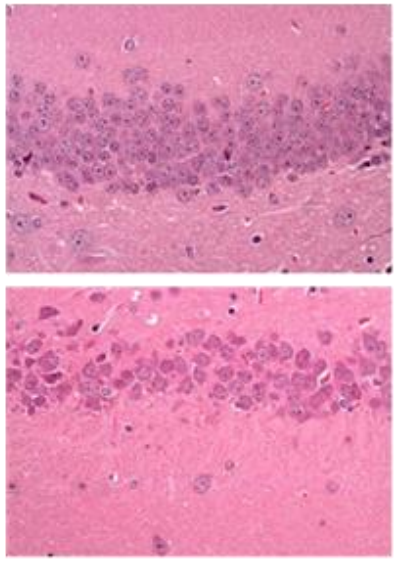

Figure 6. The hematoxylin and eosin staining of the hippocampus area in SAMP8 mice brains after 14 weeks of probiotic GKM3 consumption. GKM3-L: $1.0 \times 10^{9} \mathrm{CFU} / \mathrm{kg}$ BW/day (low dose); GKM3-H: $5.1 \times 10^{9} \mathrm{CFU} / \mathrm{kg}$ BW/day (high dose)

\section{Discussion}

There were no significant difference in the body weight or food intake between the control group and the probiotic groups (Table 1). This indicates that the probiotic GKM3 is safe and non-toxic to the mammal. Under the same metabolic parameter and 
energy consumption, the effects of anti-aging in GKM3-fed SAMP8 can be discussed in the following section.

Through observation of the lifespan of SAMP8, we note the death started from 6-7 months; however, both males and females in the probiotic GKM3-H group tended to present low death rates (Figure 1). Especially up to 11 months, the survival rates were very different. The GKM3-H group still kept $90-95 \%$ of the survival rate but the control group only presented $60-40 \%$ of the survival rate. Compared with other reported nutrients such as plant extract or marine sources on anti-aging effect, probiotic GKM3 provided a better result especially in terms of a longer survival rate [32,33]. It is possible that those anti-aging materials contained lipid, organic acid, polyphenols, or vitamins, which also can be easily found from the probiotic's fermentation, and resulted in a longer lifespan [34-36].

Behavior avoidance tests are usually used for evaluating learning and memory in subjects. Memory is defined as a behavioral change caused by an experience, while learning is defined as a process for acquiring memory [37]. Both memory and learning were formed or achieved by being involved with nerve transmission and the nerve cell. Hence, the process of aging could increase the accumulation of ROS in neurons and damage the cell, resulting in poor memory and learning ability [38]. The passive avoidance test is a fearmotivated test in which subjects are required to inhibit a previously exhibited response [39]. Mouse with a better memory and learning ability can avoid entering dangerous areas. Conversely, active avoidance requires subjects to emit a response such as running to a safe place to avoid a noxious stimuli. Good memory and learning skills help the mice respond to alerting events and avoid incoming dangers. Evidence from our study showed that probiotic GKM3 could contribute to learning and memory by inhibiting the occurrence of undesirable responses, while there was no contribution in the control group even after the training procedure (Figure 2). Interestingly, the control group showed an increased tendency in the successful avoidance followed by the training days in the active avoidance test; however, the group fed with probiotic GKM3 showed a stronger significant successful avoidance (Figure 3). This could be explained by the trial-designed base [40]. Mice were forced to learn what to do in the active avoidance test but were relatively unstimulated in being required to learn what not to do in the passive avoidance test. In spite of the different reactions presented by the control mice, the effect of probiotic GKM3 in improving learning and memory could not be denied with the stimulations of both different mechanisms [41].

Similar behavior results were reported by Yong et al. with chicken extract as a diet addition and Su et al. with the supplementation of yam for SAMP8 mice [40,41]. As the bioactive compounds should exhibit a tremendous difference between the meat extract and plant origin, it could be speculated that the effect of cognitive maintenance was highly related to the alteration of gut microbiota [42,43]. Probiotics can produce metabolic compounds that enhance or suppress the growth of certain gut microorganisms [44]. These metabolic compounds, such as peptides, cortisol, or SCFAs, can also modulate the nervous system and maintain brain functions through the gut-microbiome-brain interaction. It was found that the gut microbiota in centenarians was very different from the aging population [45]. In particular, the relative abundance of Firmicutes was found. Even though we did not analyze the microbiota in this study, several papers pointed out that the administration of probiotics altered the gut microbiota [46-50]. In addition, our unrevealed data concerning a probiotic mixture maily contained L. plantarum GKM3 in a clinical trial that showed an increase of several Bifidobacterium species and several Lactobacillus species in the stool analysis after four weeks of consumption. It is suggested that L. plantarum GKM3 may maintain brain functions by changing the composition of gut microbial flora [51].

SAMP8 is a neuropathological model of accelerated brain aging derived from an AKR/J breeding colony by Professor Toshio Takeda at the Kyoto University [52]. Regarding ageassociated morphological alteration, early amyloid accumulation in the hippocampus was found in SAMP8 mice, which resulted in learning disturbances and impaired memory [53]. $A \beta$ was considered to induce ROS formation, lipid peroxidation, and neurotoxicity in hippocampal neurons [54]. Our results reveal that probiotic GKM3 not only inhibited 
oxidative stress in the brain (Figure 4) but also was involved in the upper inhibition of the amyloid formation (Figure 5). TBARS is formed as a by-product of lipid peroxidation and MDA is formed as its end-product. 8-OHdG is a common end-product of deoxyribonucleic acid (DNA) oxidation. That is, high levels of TBARS and 8-OHdG both represent strong oxidation and result in cognitive impairment [55].

Pyramidal cells, a type of populous neuron involved with the sensory and motor cues in the hippocampus, could contribute to information processing, learning, and memory [56]. The disordered arrangements of pyramidal cells in the hippocampal CA1 region were found in Alzheimer's disease-affected mice [57]. It is indicated that L. plantarum GKM3 could alleviate the functional decline of neuron-transmitting by maintaining cell morphology (Figure 6). That is, long-term administration of probiotic GKM3 could enhance a better consciousness and encourage appropriate actions in life.

\section{Conclusions}

In this study, we examined the dose-dependent effect of long-term administration of L. plantarum GKM3 on longevity in both male and female SAMP8 mice. In addition, supplementation of probiotic GKM3 showed the improvement of memory and learning ability by being involved in anti-oxidative stress, by lowering $A \beta$ accumulation, and by maintaining the arrangement of nerve cells in the hippocampus. These results suggest that probiotic L. plantarum GKM3 could act as an antioxidant for delaying the aging process and prevent age-related cognitive impairment. With its desirable functions and safe consumption history, L. plantarum GKM3 is a promising probiotic supplementation for the elderly.

Author Contributions: T.J.F. and Y.-L.C. provided the ideas and conceived the experiments. M.-F.W. operated the animal model and conducted biochemical analysis. W.-H.L. contributed to the statistics. C.-C.C. gave advice for the discussion. S.-W.L. collected the data and wrote the paper. Y.-S.T. revised the manuscript. All authors have read and agreed to the published version of the manuscript.

Funding: This research received no external funding.

Institutional Review Board Statement: The study was conducted according to the guidelines of the Institutional Animal Care and Use Committee in Providence University (Taichung City, Taiwan) with the number 20170629-A02.

Informed Consent Statement: Not applicable.

Data Availability Statement: All data can be assessed from W.S. Lin via the email address.

Acknowledgments: We thank Jiunn-Wang Liao from the Graduate Institute of Veterinary Pathobiology, National Chung Hsing University (Taichung, Taiwan), for helping us with the tissue slicing and pathological examination. We also give a special thanks to Tseng Andrew, Chief Executive Officer, at Grape King Bio Ltd. (Taoyuan, Taiwan) for his permission on providing probiotics dry powder with mass production as the sample in this experiment.

Conflicts of Interest: The authors declare no conflict of interest.

\section{References}

1. Boustani, M.; Baker, M.S.; Campbell, N.; Munger, S.; Hui, S.L.; Castelluccio, P.; Farber, M.; Guzman, O.; Ademuyiwa, A.; Miller, D.; et al. Impact and recognition of cognitive impairment among hospitalized elders. J. Hosp. Med. 2010, 5, 69-75. [CrossRef] [PubMed]

2. Prince, M.J.; Guerchat, M.M.; Prina, M. The Epidemiology and Impact of Dementia—Current State and Future Trends; World Health Organization: Geneva, Switzerland, 2015.

3. Liguori, I.; Russo, G.; Curcio, F.; Bulli, G.; Aran, L.; Della-Morte, D.; Gargiulo, G.; Testa, G.; Cacciatore, F.; Bonaduce, D.; et al. Oxidative stress, aging, and diseases. Clin. Interv. Aging 2018, 13, 757. [CrossRef] [PubMed]

4. Pham-Huy, L.A.; He, H.; Pham-Huy, C. Free radicals, antioxidants in disease and health. Int. J. Biomed. Sci. 2008, 4, 89. [PubMed]

5. Xia, S.; Zhang, X.; Zheng, S.; Khanabda, R. An update on inflamm-aging: Mechanisms, prevention, and treatment. J. Immunol. Res. 2016, 2016, 8426874. [CrossRef] [PubMed]

6. Janson, M. Orthomolecular medicine: The therapeutic use of dietary supplements for anti-aging. Clin. Interv. Aging 2006, 1, 261-265. [CrossRef] 
7. Pan, M.H.; Lai, C.S.; Tsai, M.L.; Wu, J.C.; Ho, C.T. Molecular mechanisms for anti-aging by natural dietary compounds. Mol. Nutr. Food Res. 2012, 56, 88-115. [CrossRef]

8. Shin, K.K.; Yi, Y.S.; Kim, J.K.; Kim, H.; Hossain, M.A.; Kim, J.H.; Cho, J.Y. Korean red ginseng plays an anti-aging role by modulating expression of aging-related genes and immune cell subsets. Molecules 2020, 25, 1492. [CrossRef] [PubMed]

9. Sharma, H.S.; Drieu, K.; Alm, P.; Westman, J. Role of nitric oxide in blood-brain barrier permeability, brain edema and cell damage following hyperthermic brain injury: An experimental study using EGB-761 and Gingkolide B pretreatment in the rat. Acta Neurochir. Suppl. 2000, 76, 81-86. [CrossRef]

10. Ayaz, M.; Sadiq, A.; Junaid, M.; Ullah, F.; Subhan, F.; Ahmed, J. Neuroprotective and anti-aging potentials of essential oils from aromatic and medicinal plants. Front. Aging Neurosci. 2017, 9, 168. [CrossRef]

11. Cui, X.; Lin, Q.; Liang, Y. Plant-Derived Antioxidants Protect the Nervous System From Aging by Inhibiting Oxidative Stress. Front. Aging Neurosci. 2020, 12, 209. [CrossRef]

12. Miller, M.G.; Thangthaeng, N.; Poulose, S.M.; Shukitt-Hale, B. Role of fruits, nuts, and vegetables in maintaining cognitive health. Exp. Gerontol. 2017, 94, 24-28. [CrossRef]

13. Coman, V.; Vodnar, D.C. Gut microbiota and old age: Modulating factors and interventions for healthy longevity. Exp. Gerontol. 2020, 141, 111095. [CrossRef]

14. Maynard, C.; Weinkove, D. Bacteria increase host micronutrient availability: Mechanisms revealed by studies in C. elegans. Genes Nutr. 2020, 15, 4. [CrossRef]

15. Rahim, M.B.H.A.; Chilloux, J.; Martinez-Gili, L.; Neves, A.L.; Myridakis, A.; Gooderham, N.; Dumas, M.E. Diet-induced metabolic changes of the human gut microbiome: Importance of short-chain fatty acids, methylamines and indoles. Acta Diabetol. 2019, 56, 493-500. [CrossRef] [PubMed]

16. McClanahan, D.; Yeh, A.; Firek, B.; Zettle, S.; Rogers, M.; Cheek, R.; Nguyen, M.V.L.; Gayer, C.P.; Wendell, S.G.; Mullet, S.J.; et al. Pilot study of the effect of plant-based enteral nutrition on the gut microbiota in chronically ill tube-fed children. J. Parenter. Enter. Nutr. 2019, 43, 899-911. [CrossRef] [PubMed]

17. Gill, P.A.; Van Zelm, M.C.; Muir, J.G.; Gibson, P.R. Short chain fatty acids as potential therapeutic agents in human gastrointestinal and inflammatory disorders. Aliment. Pharmacol. Ther. 2018, 48, 15-34. [CrossRef] [PubMed]

18. Frost, G.; Sleeth, M.L.; Sahuri-Arisoylu, M.; Lizarbe, B.; Cerdan, S.; Brody, L.; Anastasovska, J.; Ghourab, S.; Hankir, M.; Zhang, S.; et al. The short-chain fatty acid acetate reduces appetite via a central homeostatic mechanism. Nat. Commun. 2014, 5, 3611. [CrossRef]

19. Ganapathy, V.; Thangaraju, M.; Prasad, P.D.; Martin, P.M.; Singh, N. Transporters and receptors for short-chain fatty acids as the molecular link between colonic bacteria and the host. Curr. Opin. Pharmacol. 2013, 13, 869-874. [CrossRef]

20. Wu, L.; Zeng, A.; Rubino, S.; Kelvin, D.J.; Carru, C. A cross-sectional study of compositional and functional profiles of gut microbiota in Sardinian centenarians. Msystems 2019, 4, e00325-19. [CrossRef]

21. Wu, L.; Zinellu, A.; Milanesi, L.; Rubino, S.; Kelvin, D.J.; Carru, C. Gut Microbiota Pattern of Centenarians. In Centenarians; Springer: Berlin, Germany, 2019; pp. 149-160. [CrossRef]

22. Scott, K.A.; Ida, M.; Peterson, V.L.; Prenderville, J.A.; Moloney, G.M.; Izumo, T.; Murphy, K.; Murphy, A.; Ross, R.P.; Stanton, C.; et al. Revisiting Metchnikoff: Age-related alterations in microbiota-gut-brain axis in the mouse. Brain Behav. Immun. 2017, 65, 20-32. [CrossRef]

23. Kesika, P.; Suganthy, N.; Sivamaruthi, B.S.; Chaiyasut, C. Role of gut-brain axis, gut microbial composition, and probiotic intervention in Alzheimer's disease. Life Sci. 2020, 264, 118627. [CrossRef] [PubMed]

24. Mazzoli, R.; Pessione, E. The neuro-endocrinological role of microbial glutamate and GABA signaling. Front. Microbiol. 2016, 7, 1934. [CrossRef] [PubMed]

25. Yunes, R.A.; Poluektova, E.U.; Vasileva, E.V.; Odorskaya, M.V.; Marsova, M.V.; Kovalev, G.I.; Danilenko, V.N. A multi-strain potential probiotic formulation of GABA-producing Lactobacillus plantarum 90sk and Bifidobacterium adolescentis 150 with antidepressant effects. Probiotics Antimicrob. Proteins 2020, 12, 973-979. [CrossRef] [PubMed]

26. Ni, Y.; Yang, X.; Zheng, L.; Wang, Z.; Wu, L.; Jiang, J.; Yang, T.; Ma, L.; Fu, Z. Lactobacillus and Bifidobacterium improves physiological function and cognitive ability in aged mice by the regulation of gut microbiota. Mol. Nutr. Food Res. 2019, 63, 1900603. [CrossRef]

27. Westfall, S.; Lomis, N.; Kahouli, I.; Dia, S.Y.; Singh, S.P.; Prakash, S. Microbiome, probiotics and neurodegenerative diseases: Deciphering the gut brain axis. Cell. Mol. Life Sci. 2017, 74, 3769-3787. [CrossRef]

28. Hammes, W.P.; Vogel, R.F. The genus lactobacillus. In The Genera of Lactic Acid Bacteria; Springer: Berlin, Germany, $1995 ;$ pp. 19-54.

29. Hsu, C.L.; Hou, Y.H.; Wang, C.S.; Lin, S.W.; Jhou, B.I.; Chen, C.C.; Chen, Y.L. Antiobesity and uric acid-lowering effect of Lactobacillus plantarum GKM3 in high-fat-diet-induced obese rats. J. Am. Coll. Nutr. 2019, 38, 623-632. [CrossRef]

30. Tsai, Y.S.; Lin, S.W.; Chen, Y.L.; Chen, C.C. Effect of probiotics Lactobacillus paracasei GKS6, L. plantarum GKM3, and L. rhamnosus GKLC1 on alleviating alcohol-induced alcoholic liver disease in a mouse model. Nutr. Res. Pract. 2020, 14, 299-308. [CrossRef]

31. Shih, Y.T.; Lin, S.W.; Wang, C.S.; Chen, Y.L.; Lin, W.H.; Tsai, P.C.; Chen, C.C. Effect of Probiotic Lactobacillus plantarum GKM3 on OVA-Induced Asthma in Mice. J. Financ. Quant. Anal. 2019, 8, 126-132. [CrossRef]

32. Lin, W.S.; Chen, J.Y.; Wang, J.C.; Chen, L.Y.; Lin, C.H.; Hsieh, T.R.; Wang, M.F.; Fu, T.F.; Wang, P.Y. The anti-aging effects of Ludwigia octovalvis on Drosophila melanogaster and SAMP8 mice. Age 2014, 36, 689-703. [CrossRef] 
33. Ueda, Y.; Wang, M.F.; Irei, A.V.; Sarukura, N.; Sakai, T.; Hsu, T.F. Effect of dietary lipids on longevity and memory in the SAMP8 mice. J. Nutr. Sci. Vitaminol. 2011, 57, 36-41. [CrossRef]

34. Román, G.; Jackson, R.E.; Román, A.N.; Reis, J. Mediterranean diet: The role of long-chain $\omega-3$ fatty acids in fish; polyphenols in fruits, vegetables, cereals, coffee, tea, cacao and wine; probiotics and vitamins in prevention of stroke, age-related cognitive decline, and Alzheimer disease. Rev. Neurol. 2019, 175, 724-741. [CrossRef]

35. Szutowska, J. Functional properties of lactic acid bacteria in fermented fruit and vegetable juices: A systematic literature review. Eur. Food Res. Technol. 2020, 246, 357-372. [CrossRef]

36. Shang, Q.; Jiang, H.; Hao, J.; Li, G.; Yu, G. Gut microbiota fermentation of marine polysaccharides and its effects on intestinal ecology: An overview. Carbohydr. Polym. 2018, 179, 173-185. [CrossRef] [PubMed]

37. Okano, H.; Hirano, T.; Balaban, E. Learning and memory. Proc. Natl. Acad. Sci. USA 2000, 97, 12403-12404. [CrossRef] [PubMed]

38. Oswald, M.C.; Garnham, N.; Sweeney, S.T.; Landgraf, M. Regulation of neuronal development and function by ROS. FEBS Lett. 2018, 592, 679-691. [CrossRef]

39. Sprott, R.L.; Stavnes, K.L. Active-and passive-avoidance learning in inbred mice: Transfer of training effects. Anim. Learn. Behav. 1974, 2, 225-228. [CrossRef]

40. Ohta, A.; Hirano, T.; Yagi, H.; Tanaka, S.; Hosokawa, M.; Takeda, T. Behavioral characteristics of the SAM-P/8 strain in Sidman active avoidance task. Brain Res. 1989, 498, 195-198. [CrossRef]

41. Branchi, I.; Ricceri, L. Active and passive avoidance. In Behavioral Genetics of the Mouse: Volume 1; Cambridge University Press: Cambridge, UK, 2013; pp. 291-298.

42. Chou, M.Y.; Chen, Y.J.; Lin, L.H.; Nalao, Y.; Lin, A.L.; Wang, M.F.; Yong, S.M. Protective Effects of Hydrolyzed Chicken Extract (Probeptigen ${ }^{\circledR} / \mathrm{Cmi}-168$ ) on Memory Retention and Brain Oxidative Stress in Senescence-Accelerated Mice. Nutrients 2019, 11, 1870. [CrossRef]

43. Chan, Y.C.; Hsu, C.K.; Wamg, M.F.; Su, T.Y. A diet containing yam reduces the cognitive deterioration and brain lipid peroxidation in mice with senescence accelerated. Int. J. Food Sci. Technol. 2004, 39, 99-107. [CrossRef]

44. Peera, H.; Versalovic, J. Effects of probiotics on gut microbiota: Mechanisms of intestinal immunomodulation and neuromodulation. Ther. Adv. Gastroenterol. 2013, 6, 39-51. [CrossRef]

45. Kim, B.S.; Choi, C.W.; Shin, H.; Jin, S.P.; Bae, J.S.; Han, M.; Seo, E.Y.; Chun, J.; Chung, J.H. Comparison of the gut microbiota of centenarians in longevity villages of South Korea with those of other age groups. Korean J. Microbiol. Biotechnol. 2019, 29, 429-440. [CrossRef]

46. Scott, K.P.; Gratz, S.W.; Sheridan, P.O.; Fibt, H.J.; Duncan, S.H. The influence of diet on the gut microbiota. Pharmacol. Res. 2013, 69, 52-60. [CrossRef]

47. Flint, H.J.; Duncan, S.H.; Scott, K.P.; Louis, P. Links between diet, gut microbiota composition and gut metabolism. Proc. Nutr. Soc. 2015, 74, 13-22. [CrossRef]

48. Iannone, L.F.; Preda, A.; Blottière, H.M.; Clarke, G.; Albani, D.; Belcastro, V.; Carotenuto, M.; Cattaneo, A.; Citraro, R.; Ferraris, C.; et al. Microbiota-gut brain axis involvement in neuropsychiatric disorders. Expert. Rev. Neurother. 2019, 19, 1037-1050. [CrossRef] [PubMed]

49. He, Q.; Hou, Q.; Wang, Y.; Shen, L.; Sun, Z.; Zhang, H.; Liong, M.; Kwok, L. Long-term administration of Lactobacillus casei Zhang stabilized gut microbiota of adults and reduced gut microbiota age index of older adults. J. Funct. Foods. 2020, 64, 103682. [CrossRef]

50. Bagga, D.; Reichert, J.L.; Koschuting, K.; Aigner, C.S.; Holzer, P.; Koskinen, K.; Moissl-Eichinger, C.; Schöpf, V. Probiotics drive gut microbiome triggering emotional brain signatures. Gut Microbes 2018, 9, 486-496. [CrossRef] [PubMed]

51. Tooley, K.L. Effects of the Human Gut Microbiota on Cognitive Performance, Brain Structure and Function: A Narrative Review. Nutrients 2020, 12, 3009. [CrossRef] [PubMed]

52. Akiguchi, I.; Pallàs, P.; Budka, H.; Akiyama, H.; Ueno, M.; Han, J.; Yagi, H.; Nishikawa, T.; Chiba, Y.; Sugiyama, H. SAMP8 mice as a neuropathological model of accelerated brain aging and dementia: Toshio Takeda's legacy and future directions. Neuropathology 2017, 37, 293-305. [CrossRef]

53. del Valle, J.; Duran-Vilaregut, J.; Manich, G.; Casadesús, G.; Smith, A.M.; Camins, A.; Pallàs, M.; Pelegrí, C.; Vilaplana, J. Early amyloid accumulation in the hippocampus of SAMP8 mice. J. Alzheimer's Dis. 2010, 19, 1303-1315. [CrossRef] [PubMed]

54. Allan Butterfield, D. Amyloid $\beta$-peptide (1-42)-induced oxidative stress and neurotoxicity: Implications for neurodegeneration in Alzheimer's disease brain. A review. Free Radic. Res. 2002, 36, 1307-1313. [CrossRef]

55. Liu, Z.; Liu, Y.; Tu, X.; Shen, H.; Qiu, H.; Chen, H.; He, J. High serum levels of malondialdehyde and 8-OHdG are both associated with early cognitive impairment in patients with acute ischaemic stroke. Sci. Rep. 2017, 7, 9493. [CrossRef] [PubMed]

56. Graves, A.R.; Moore, M.J.; Bloss, E.B.; Mensh, B.D.; Kath, W.L.; Spruston, N. Hippocampal pyramidal neurons comprise two distinct cell types that are countermodulated by metabotropic receptors. Neuron 2012, 76, 776-789. [CrossRef] [PubMed]

57. Chen, F.Z.; Zhao, Y.; Chen, H.Z. MicroRNA-98 reduces amyloid $\beta$-protein production and improves oxidative stress and mitochondrial dysfunction through the Notch signaling pathway via HEY2 in Alzheimer's disease mice. Int. J. Mol. Med. 2019, 43, 91-102. [CrossRef] [PubMed] 